\title{
Evaluation of Human Errors Using Standardized Plan Analysis Risk among Health Provider in Clinical and Pathology Laboratories in Hospitals of Qazvin Province

\author{
${ }^{1}$ Seyed Amir Farzam, ${ }^{2}$ Zohre Sahraei, ${ }^{3}$ Elham Khodabandehloo, ${ }^{4}$ Habib Sadeghi Rad, ${ }^{5}$ Mohammad Reza \\ Modabber, ${ }^{*}$ Yousef Khazaei Monfared \\ ${ }^{1}$ Assistant Professor of Anatomical and Clinical Pathology, Faculty of Medicine, Qazvin University of Medical \\ Sciences, Qazvin, Iran \\ ${ }^{2}$ M.Sc. of Health Information Technology, School of Public Health, Shahid Beheshti University of Medical \\ Sciences, Tehran, Iran \\ ${ }^{3}$ B.Sc of Medical Laboratory Scientist, Qazvin University of Medical Sciences, Qazvin, Iran \\ ${ }^{4}$ Department of Medical Genetics, School of Medicine, Tehran University of Medical Sciences, Tehran, Iran \\ ${ }^{5} \mathrm{MD}$, MPH, PhD Candidate in Health Care Management, Social Determinants of Health Research Center, Qazvin \\ University of Medical Sciences, Qazvin, Iran \\ ${ }^{* 6}$ M.Sc of Medical Biotechnology, Dezful University of Medical Sciences, Dezful, Iran \\ Email: khazaei_yoosef@outlook.com
}



\begin{abstract}
Introduction: Damage due to human error has different consequences in different professions. Small mistakes can lead to irreparable damages and high costs in the health care profession. Therefore, the purpose of this study was to identify human error using the SPAR-H in clinical and pathology laboratories in hospitals of Qazvin province. Method: This study was a cross-sectional study which was conducted in 15 hospitals of Qazvin in 2018. The target groups was of professional staff in clinical and pathology laboratories comprised 150 staffs who they were included as an available sampling . At first, task analysis was conducted to target group using Hierarchical Task Analysis (HTA) technique by FGD. In next step, the Human Error Probability (HEP) was determined utilizing SPAR-H method and dependences of performance-shaping factors (PSFs) and action and diagnosis activities were identified. And finally, the errors were detected. Result: According to the findings of the study, in the laboratory, $12 \%$ of the diagnostic errors, $48 \%$ of the functional and $40 \%$ of the compound were evaluated. The most probable error was the error in entering the results and values from the manual recording to the computer with a 1\% probability error and the least probable error was the Corrupted or lost samples with an error probability of $0.00125 \%$. Conclusion: Considering the fact that the highest number of reported errors occurred at the patient's admission stage, including the inclusion of patient information and incorrect registration of the requested tests, and given the high volume of patients referred to hospital laboratories, especially public hospitals due to acceptance of treatment insurance And the low cost, it is necessary to allocate more personnel in the acceptance and response department.
\end{abstract}

\section{Keywords}

Medical Error, SPAR-H, Laboratory Staff, Qazvin

\section{Introduction}

Human errors are one of the issues that have attracted a considerable part of the time, budget, and attention of specialists and managers in the world of theoretical and practical management today. The organizational structure of the staff of an organization is one of the factors that plays an effective role in reducing human error.(1) Damage due to human error has different consequences in different professions and small mistakes can lead to catastrophic dimensions in important and sensitive businesses. Human errors that deals with the lives of people can lead to irreparable damages and high costs in the health care profession.(2-3) Human errors in the medical profession called medical error are The failure to do the right thing or the wrong acts in planning or execution that inactivates or potentially causes an unwanted event that results in death, prolongation of hospitalization or disability when discharged. These mistakes include diagnostic errors, mistakes in prescribing drugs and therapies, errors in surgical procedures, mistakes in the use of technology and equipment, mistakes in the interpretation of Para clinical tests, etc.(4)The review of resources shows that the mistakes of medical professions are less studied than other occupations in Iran and other countries. Various studies globally suggest that human error in these occupations has imposed heavy costs on patients by imposing additional costs of health care due to error, disability, and income reduction. In addition, these errors can lead to a reduction in patient's trust in the therapeutic care system, as well as a decrease in the patient's 
satisfaction.(5) According to the Starfield Institute of the American Academy Institute of Medicine, Medical errors in hospitals and health care organizations in the United States (including drug errors, laboratory errors, diagnosis errors, surgical errors, radiological errors, etc.) after cardiovascular and cancers, is the third most common cause of death, and nearly 98,000 deaths occur each year due to these errors; in 2008, only 17.1 billion dollars were spent on errors measurable in US hospitals.(6-7) Among the providers of services to patients, laboratories has a high impact on patient safety, with $90-80 \%$ of medical diagnosis based on the results of laboratory tests. So, laboratory errors can lead to delay in treatment or false treatment, a As a result, additional costs and increased risks are for the patients.[8] The attitude of medical personnel to reporting the errors is a very important factor in preventing their occurrence and repetition (9), Because some of these adverse events are inevitable and can be repeated in the same conditions, and their experiences can be attributed to others documented and repeatedly abandoned them (10). In this regard, several methods have been presented to evaluate human error capabilities such as HEART, THERP, ATHENA, SPAR-H, SHERPA, etc. Among these techniques, the Standardized Plan Analysis Risk Human (SPAR-H) was first proposed by the US Nuclear Regulatory Commission (NRC) and the National Idaho National Laboratory (INL) to develop power plant safety models Nuclear design was designed And then published by Gertman et al. In 2004 in Camille and published in 2005.(11) The SPAR-H is based on reviews and troubleshooting in the first and second generation technology of the Human Reliability Assessment Process (HRA), which divides human activities into two types of functional and diagnostic activities, which can be used to classify errors and reduce the human contribution to error. In this technique, the factors affecting human function are divided into eight categories: available time, Stress/Stressors, Complexity, Experience/Training, Procedures, Ergonomics/ HMI, Fitness for Duty, Work Processes. As a result, administrators will decide more easily and awareness of the possibility of errors.(12-13) In a study that evaluated human errors in nurses of the Emergency Department of Tehran University of Medical Sciences Hospitals with SPAR-H, they concluded that the highest probability of error was related to injections of blood products with $78 \%$ and lowest probability of error the work related to the serum device with a probability of error was $55 \%$. The major causes of errors in this section were stress and complexity in the tasks of this department.(14) In the study of Rasoulzadeh et al. who investigated the human errors in the staff of medical diagnostic laboratories in Tehran and Tabriz in 2014, They found that the error rate was $57.4 \%$ in the admission phase and at 42.6 in the response phase.(15) Considering the importance and sensitivity of laboratory work and the necessity to recognize and control human errors in order to improve the quality of care and safety of patients The present study was conducted with the aim of identifying and evaluating human errors using SPAR-H technique in medical diagnostic laboratories of Qazvin hospitals.

\section{Method}

This study was a cross-sectional study that was carried out during 2018 in eight general and seven private hospitals of Qazvin province. The target groups was of professional staff of the laboratory in clinical and pathology laboratories comprised 150 staffs who they were included as an available sampling. SPAR-H technique was used to investigate the human error in the community, which was carried out in accordance with the following steps, respectively.

1. In the first step, the analysis of tasks by Hierarchical Task Analysis (HTA)(16) was performed independently for each group of diagnostic and practical activities related to the studied groups. Diagnostic activities include interpretation and decision-making and relies on knowledge and experience to understand existing conditions, plan, prioritize activities, and determine appropriate practices. Functional activities also include one or more activities identified by diagnosis, operational rules, and guidelines.

2. The second step, at this stage, the probability of human error in each task was determined, so that the diagnostic and action sheet for each task after entering the basic information affecting the error including age, gender, work history, education, presence of the researcher after completing the necessary information, the subjects were completed. This step of the study took the form of the following steps:

\section{PART I: EVALUATE EACH PSF FOR DIAGNOSIS Or Action:}

A) Evaluate PSFs for the Diagnosis Or Action Portion of the Task, If Any. At this stage, each performance shaping factor was evaluated for diagnosis or task performance. PSF include available time, Stress/Stressors, Complexity, Experience/Training, Procedures, Ergonomics/ HMI, Fitness for Duty, Work Processes.(17-18) Each of these PSF has specific coefficients. Determine each of the PSF in the diagnostic and practical worksheet first by using direct observation techniques and without interfering with the routine task of the laboratories, radiology and services groups by the analyst, and then by interviewing the personnel high working experience. The recording of the interview was carried out using a note taking method.

B) Calculate the Diagnosis and Actions Failure Probability: 
(1) If all PSF ratings are nominal, then the Diagnosis and Actions Failure probability are respectively 1.0E-2 and $1.0 \mathrm{E}-3$.

(2) Otherwise, the Diagnosis Failure Probability is: 1.0E-2 x Time x Stress or Stressors x Complexity x Experience or Training x Procedures x Ergonomics or HMI x Fitness for Duty x Processes, the Action Failure Probability is: 1.0E-3 x Time x Stress or Stressors x Complexity x Experience or Training x Procedures x Ergonomics or HMI x Fitness for Duty x Processes.

C) Calculate the Adjustment Factor IF Negative Multiple ( $\geq 3$ ) PSFs are Present. When 3 or more negative PSF influences are present, in lieu of the equation above, you must compute a composite PSF score used in conjunction with the adjustment factor. Negative PSFs are present anytime a multiplier greater than 1 is selected. The Nominal HEP (NHEP) is 1.0E-2 for Diagnosisan and 1.0E-3 for Action. The composite PSF score is computed by multiplying all the assigned PSF values. Then the adjustment factor below is applied to compute the HEP: HEP $=$ NHEP.PSF/NHEP(PSF-1) +1

D. Record Final Diagnosis or Action HEP. If no adjustment factor was applied, record the value from Part B as your final diagnosis HEP. If an adjustment factor was applied, record the value from Part C.

PART II: CALCULATE TASK FAILURE PROBABILITY WITHOUT FORMAL DEPENDENCE (PW/OD): Calculate the Task Failure Probability Without Formal Dependence (Pw/od) by adding the Diagnosis Failure Probability from Part I and the Action Failure Probability from Part II. In instances where an action is required without a diagnosis and there is no dependency, then this step is omitted.

\section{Part III: DEPENDENCY:}

For all tasks, except the first task in the sequence, use the table and formulae below to calculate the Task Failure Probability With Formal Dependence (Pw/d). If there is a reason why failure on previous tasks should not be considered, such as it is impossible to take the current action unless the previous action has been properly performed, explain here: First task in sequence.

Dependency Condition Table: Using Pw/od = Probability of Task Failure Without Formal Dependence (calculated in Part III):

For Complete Dependence the probability of failure is 1.0

For High Dependence the probability of failure is $(1+\mathrm{Pw} / \mathrm{od}) / 2$

For Moderate Dependence the probability of failure is $(1+6 \times \mathrm{Pw} / \mathrm{od}) / 7$

For Low Dependence the probability of failure is $(1+19 \times \mathrm{Pw} / \mathrm{od}) / 20$

For Zero Dependence the probability of failure is Pw/od

\section{Results}

Analysis of the results of demographic information showed that $64 \%$ of the participants in the study were women with an average age of 34 years and $36 \%$ of them were men with an average age of 38 , of which $12 \%$ were associate, $75 \%$ were bachelor and $13 \%$ were masters. Their average work experience was 14 years. Based on the results, there was no significant relationship between sex, age and educational status ( $\mathrm{p}>0.05)$. But there was a meaningful relationship with the average work experience. According to the findings from this study in the laboratories activities, $12 \%$ of the diagnostic errors, $48 \%$ of the functional and $40 \%$ of the compound were evaluated.

\begin{tabular}{|c|c|c|c|c|c|c|}
\hline$\stackrel{z}{a}$ & Task List & Displayable Error & $\begin{array}{l}\text { The } \\
\text { Probability of } \\
\text { the Diagnosis } \\
\text { Error }\end{array}$ & $\begin{array}{c}\text { The } \\
\text { Probability } \\
\text { of the } \\
\text { Functional } \\
\text { Error } \\
\end{array}$ & $\begin{array}{c}\text { Error } \\
\text { Probability } \\
\text { without } \\
\text { Dependency } \\
\text { Factor } \\
\end{array}$ & $\begin{array}{c}\text { Error Probability } \\
\text { with Coefficient of } \\
\text { Dependency }\end{array}$ \\
\hline \multirow{5}{*}{1} & \multirow{5}{*}{ Admission } & $\begin{array}{l}\text { Incorrect recording or not } \\
\text { registering an application }\end{array}$ & 0.005 & 0.05 & 0.055 & 0.055 \\
\hline & & $\begin{array}{l}\text { Absent accurate and } \\
\text { accurate patient record }\end{array}$ & - & 0.478 & - & 0.478 \\
\hline & & $\begin{array}{l}\text { Test record called another } \\
\text { disease }\end{array}$ & - & 0.02 & - & 0.02 \\
\hline & & $\begin{array}{l}\text { Error entering the results } \\
\text { and values of the } \\
\text { handwritten sheet to the } \\
\text { computer }\end{array}$ & 0.6 & 0.4 & 1 & 1 \\
\hline & & $\begin{array}{l}\text { Error registering the } \\
\text { requested items in the } \\
\text { patient's case }\end{array}$ & 0.25 & - & - & 0.25 \\
\hline
\end{tabular}




\begin{tabular}{|c|c|c|c|c|c|c|}
\hline & & $\begin{array}{l}\text { Mismatching the accepted } \\
\text { person's profile with the } \\
\text { item submitted or missing } \\
\text { from the patient }\end{array}$ & - & 0.00225 & - & 0.00225 \\
\hline \multirow{6}{*}{2} & \multirow{6}{*}{ Sampling } & Lack of sampling skill & - & 0.015 & - & 0.015 \\
\hline & & $\begin{array}{l}\text { Inappropriate and } \\
\text { inadequate sample }\end{array}$ & - & 0.4 & - & 0.4 \\
\hline & & $\begin{array}{l}\text { Displacement and non- } \\
\text { compliance of the number } \\
\text { of patient's sample }\end{array}$ & 0.000225 & 0.002 & 0.00225 & 0.00225 \\
\hline & & Corrupted or lost samples & - & 0.00125 & - & 0.00125 \\
\hline & & $\begin{array}{l}\text { Inappropriate labeling or } \\
\text { dropping labels when } \\
\text { sampling }\end{array}$ & 0.03 & 0.3 & 0.33 & 0.33 \\
\hline & & Error in selecting test tubes & 0.0025 & - & - & 0.0025 \\
\hline \multirow{2}{*}{3} & \multirow{2}{*}{$\begin{array}{l}\text { Sample } \\
\text { isolation }\end{array}$} & $\begin{array}{l}\text { Failure to comply with } \\
\text { requirements after sampling }\end{array}$ & - & 0.22 & - & 0.22 \\
\hline & & $\begin{array}{l}\text { Problems with labeling } \\
\text { during sample isolation }\end{array}$ & 0.02 & 0.2 & 0.22 & 0.22 \\
\hline \multirow{5}{*}{4} & \multirow{5}{*}{$\begin{array}{l}\text { Carry out } \\
\text { tests in } \\
\text { different } \\
\text { parts of the } \\
\text { lab }\end{array}$} & $\begin{array}{l}\text { Do not timely testing } \\
\text { (extend the test) }\end{array}$ & - & 0.2 & 0.2 & 0.2 \\
\hline & & Mistake in testing & 0.2 & 0.02 & 0.22 & 0.22 \\
\hline & & $\begin{array}{l}\text { Inadequate personnel skills } \\
\text { to work with the device }\end{array}$ & - & 0.005 & - & 0.005 \\
\hline & & $\begin{array}{l}\text { Interruptions in device } \\
\text { performance }\end{array}$ & - & 0.16 & - & 0.16 \\
\hline & & $\begin{array}{l}\text { Inappropriate kits and } \\
\text { materials and past history }\end{array}$ & 0.004 & - & - & 0.004 \\
\hline \multirow{3}{*}{5} & \multirow{3}{*}{$\begin{array}{l}\text { Order blood } \\
\text { transfusion } \\
\text { and blood } \\
\text { products }\end{array}$} & $\begin{array}{l}\text { Sending blood with a } \\
\text { different blood type to the } \\
\text { patient's blood type }\end{array}$ & 0.022 & 0.0125 & 0.0345 & 0.0345 \\
\hline & & $\begin{array}{l}\text { Failure to maintain proper } \\
\text { blood transfusion products }\end{array}$ & 0.004 & 0.0005 & 0.0045 & 0.0045 \\
\hline & & Blood bank failures & 0.1 & 0.008 & 0.018 & 0.018 \\
\hline \multirow{3}{*}{6} & \multirow{3}{*}{ Answer } & Wrong typing & - & 0.81 & - & 0.81 \\
\hline & & Incorrect report & 0.0016 & 0.0001 & 0.0017 & 0.0017 \\
\hline & & Delayed response & - & 0.6 & 0.6 & 0.6 \\
\hline
\end{tabular}

Table 1. Human Error Probability (Laboratory)

Among the diagnostic errors, the highest error rate was related to Error registering the requested items in the patient's case with $0.25 \%$, And the lowest error rate was related to the probability of Error in selecting test tubes with $0.0025 \%$. Among the functional errors, the highest rate was related to Wrong typing with 0.81 and the lowest rate was the probability of error in Corrupted or lost samples with $0.000125 \%$. Among the composite error, the most probable error was related to to the error in entering the results and values from the manual record sheet to the computer with $1 \%$ probability error and the lowest probability error was related to the Incorrect report with the probability of $0.0017 \%$ (Table 1). The results of the study indicated that the most probable error related to the error in entering the results and values from the manual record sheet to the computer with $1 \%$ probability error and the least probable error of the failure or loss of the sample with the probability of error 0.00125 Percentage. In Table 2 , the errors are prioritized to the probability sequence.

\begin{tabular}{|r|l|c|}
\hline \multicolumn{1}{|c|}{ Displayable Error } & The Probability of Error \\
\hline 1 & Error entering the results and values of the handwritten sheet to the computer & 1 \\
\hline 2 & Wrong typing & 0.81 \\
\hline 3 & Delayed response & 0.6 \\
\hline 4 & Absent accurate and accurate patient record & 0.478 \\
\hline 5 & Inappropriate and inadequate sample & 0.4 \\
\hline 6 & Inappropriate labeling or dropping labels when sampling & 0.33 \\
\hline 7 & Error accepting requested items in patient's case & 0.25 \\
\hline 8 & Mistake in testing & 0.22 \\
\hline 9 & Failure to comply with requirements after sampling & 0.22 \\
\hline 10 & Problems with labeling during sample isolation & 0.21 \\
\hline 11 & Failure to timely test (length of experiment) & 0.2 \\
\hline 12 & Inappropriate kits and materials and past history & 0.16 \\
\hline 13 & Incorrect recording or not registering an application & 0.055 \\
\hline 14 & Sending blood with a different blood type to the patient's blood type & 0.0345 \\
\hline 15 & Test record called another disease & 0.02 \\
\hline
\end{tabular}




\begin{tabular}{|r|l|c|}
\hline 16 & Blood bank failures & 0.018 \\
\hline 17 & Lack of sampling skill & 0.015 \\
\hline 18 & Inadequate personnel skills to work with the device & 0.005 \\
\hline 19 & Failure to maintain proper blood transfusion products & 0.0045 \\
\hline 20 & Inappropriate kits and materials and past history & 0.004 \\
\hline 21 & Displacement and incompatibility of the patient's sample number and patient name & 0.00225 \\
\hline 22 & Mismatching the accepted person's profile with the item submitted or missing from the patient & 0.0025 \\
\hline 23 & Error in selecting test tubes & 0.0025 \\
\hline 24 & Incorrect report & 0.0017 \\
\hline 25 & Corrupted or lost samples & 0.00125 \\
\hline
\end{tabular}

Table 2: Prioritization of Errors in Order of Occurrence

\section{Discussion}

The present study was conducted with the aim of identifying and evaluating human errors using SPAR-H technique in medical diagnostic laboratories of Qazvin hospitals. The results of the study showed that there was no a significant relationship between gender, age, educational status and the probability of occurrence of error in the current study. But there was a meaningful relationship with the average work record. Which was in accordance with the results of the study by Shamsi et al.(19) With increased work history, stress decreases in emergency situations, and by knowing more bottlenecks, errors can overcome the likelihood of an error in such conditions and prevent the occurrence of errors and increase patient safety. In this study, the most likely error was to the error in entering the results and values from the manual record sheet to the computer with $1 \%$ probability error and the lowest error probability was Corrupted or lost samples with a probability of 0.00125 . In the study of Rasoulzadeh et al. who examined the type and extent of human error in the staff of the acceptance and response departments of the medical diagnostic laboratories of Tehran and Tabriz during the year of 2014, it was concluded that the most incongruous errors in the laboratory section of the hospitals were incorrect entry patient information (14.6\%), error in the acceptance of the requested materials (12.4\%), inappropriate sampling $(10.1 \%)$, error in the labeling of sample containers $(9.8 \%)$ that were consistent with the current study.[15] In a study conducted in Denmark by Paul Palme in a one-year period, it was found that over $81 \%$ of laboratory errors occurred at the acceptance stage.(20) Also, in a research study conducted by Aranjna Chawla and his colleagues at the Goynd Balabh Pent Hospital in India, the rate of admission errors seen in 51244 blood samples was reported as follows: Insufficient volume of inappropriate sampling (low volume), forms in the samples taken (sampled or lipped) that were consistent with the current study.(21) A total of 33 error states were found in a study in one of the Chinese hospitals by Jiang and his colleagues using the FMEA method. Highly important hazards included sample hemolysis, sample delivery delay, sample size error, timely dissemination of results, and "failure to identify and report critical outcomes that were consistent with the results of the present study. (22) Also, in a study by Lippi and Associates, one of the most obvious errors was the hemolysis of the specimens that coincided with the present study.(23)The lysis of the specimens led to a re-test or incorrect response as a result of a misdiagnosis by the physician and complications for patients.(25) In order to prevent sample lysis, the probability of error in sampling, device performance and sample transfer or reduced.(24)

\section{Conclusion}

Since laboratories have a high impact on patient safety and $80-90 \%$ of medical diagnosis are based on the results of laboratory tests, errors in laboratory tests lead to delay in treatment or treatment, and thus additional costs and increased costs Causes the patient's dangers.[8] Considering the fact that the highest number of reported errors occurred at the patient's admission stage, including the inclusion of patient information and incorrect registration of the requested tests, and given the high volume of patients referred to hospital laboratories, especially public hospitals due to acceptance of treatment insurance And the low cost, it is necessary to allocate more personnel in the acceptance and response section, and it seems that the establishment of a system that is in terms of the quality of the laboratory support and can, in addition to the control of the laboratory, cover the errors and errors and correct training, can play an effective role in reducing the errors of laboratory.[15,24]

\section{Study Limitations}

Among the limitations of this study, it should be noted that due to the general nature of the hospital, the number of visits, the high volume of personnel, the time consuming of filling the questions related to the questionnaire and lack of staff time to complete the questionnaires, the questioner It should be referred to each department and, when writing the article, there were no internal or external articles about the possibility of error in the imaging and service sector, and this paper first evaluated the probability of errors in these two professions. 


\section{Conflicts of Interest}

There is not conflicts of interest.

\section{References}

1. Haji Hoseini A. Engineering of Human Error. 1st ed. Tehran: Fanavaran 2010: 45-66,143-101.[Persian]

2. Kllberg AS, Gransson KE, stergren J, et al. Medical errors and complaints in emergency department care in Sweden as reported by care providers, healthcare staff and patients - a national review Eur J Emerg Med. 2013;20(1):33-38.

3. Guillod O. Medical error disclosure and patient safety: legal aspects. Journal of Public Health Research. 2013;2(3): 31-185.

4. Soop M, et al. The incidence of adverse events in Swedish hospitals: a retrospective medical record review study. International Journal for Quality in Health Care 2009: 21 (4). pp: 285-291.

5. Dhingra KR, Andrew E, Hobgood C. Reducing Error in the Emergency Department: A Call for Standardization of the Sign-out Process, Ann Emerg Med. 2010; 56(6): 637-42.

6. Anderson E. Evaluating the Impact of Information Technology on Medication Errors: Simulation. Journal of the American Medical Informatics Association. 2003; 10(3): 292.

7. Kalra J, Kalra N, Baniak N. Medical error, disclosure and patient safety: A global view of quality care. Clinical Biochemistry.2013: 46 pp. 1161-1169.

8. Carraro P, Plebani M. Errors in a stat laboratory: Types and frequencies 10 years later. Clin Chem. 2007;53:1338-1342.

9. Kingston M, Evans SM, Smith BJ, Berry JG. Attitude of doctors and nurses towards incidents reporting: A qualitative analysis. Med J Aust. 2004; 181:36-39.

10. Davis RE, Sevdalis N, Neale G, et al. Hospital patients' reports of medical errors and undesirable events in their health care. J Eval Clin Pract. 2013;19(5):875-881.

11. Gertman DI, Blackman HS, Marble J, Byers J, Smith C. The SPAR-H human reliability analysis method: US Nuclear Regulatory Commission; 2005.

12. Kohn LT, Corrigan JM, Donaldson MS." To Err Is Human: Building a Safer Health Care System." Washington, DC: Institute of Medicine. 1999

13. Baker G R, et al. The Canadian Adverse Events Study: the incidence of adverse events among hospital patients in Canada. JAMC. 25 MAI 2004: 170 (11).

14. Tanha F, Mazloumi A, Faraji V, Kazemi Z, Shoghi M. Evaluation of Human Errors Using Standardized Plant Analysis Risk Human Reliability Analysis Technique among Delivery Emergency Nurses in a Hospital Affiliated to Tehran University of Medical Sciences. jhosp. 2015; 14 (3) :57-66.

15. Rasoulzadeh Y, ghaffari F, Asghari Jafarabadi M, Dianat I. The variety and rate of human error in reception staff of clinical laboratories in Tehran and Tabriz, 2014. ioh. 2016; 12 (6) :28-38.

16. Shepherd A. HTA as a framework for task analysis. Ergonomics. 1998;41(11):1537-52.

17. Gertman DI, Blackman HS, Marble J, Byers J, Smith C. The SPAR-H human reliability analysis method: US Nuclear Regulatory Commission; 2005.

18. Bell J, Holroyd J. Review of human reliability assessment methods. Health \& Safety Laboratory. 2009.

19. Shamsaii M. The viewpoints of Zabol's General Practitioners about medical errors in 2010. Bimarestan Magazine. 2012;10:1-6.

20. Bela P. FMEA: A model for reducing medical errors. Clin Chem Acta. 2009;404:75-78.

21. Chawla R, Goswami B, Tayal D, Mallika V. Identification of the Types of Preanalytical Errors in the Clinical Chemistry Laboratory. Department of Biochemistry. Pant Hospital, New Delhi, India. 2009.

22. Shashi U, Sanjay U, Rani B, Nadia J, Vinay B. Types and Frequency of reanalytical Errors in Haematology Lab. Journal of Clinical and Diagnostic Research. 2013.

23. Jiang Y, Jiang H, Ding S, Liu Q. Application of failure mode and effects analysis in a clinical chemistry laboratory. Clin Chim Acta. 2015;448:80-5. doi: 10.1016/j.cca.2015.06.016.

24. G Lippi JJ, Chance S Church, et al., Preanalytical quality improvement: from dreamto reality, Clin. Chem. Lab. Med.: CCLM/FESCC. 2011; 49. 1113-1126.

25. L Dugan L, Leech K G, Speroni J. Corriher, Factors affecting hemolysis rates in bloodsamples drawn from newly placed IV sites in the emergency department, J. Emerg.Nurs. 2005; 31: 338-345. 